Goldschmidt 2021 Abstract

https://doi.org/10.7185/gold2021.4697

\section{Chemical form of palladium and 3D distribution of Pt-group minerals in Norilsk ore deposits}

\author{
MARGARITA MERKULOVA ${ }^{1}$, JONATHAN SITTNER ${ }^{1,2}$, \\ VALERIIA BROVCHENKO $^{3}$, MARIJN BOONE ${ }^{4}$, AXEL \\ RENNO $^{2}$, JOSE RICARDO DA ASSUNCAO GODINHO ${ }^{2}$, \\ THOMAS DE SCHRYVER ${ }^{4}$, DENIS VAN LOO ${ }^{4}$, ANTTI \\ ROINE $^{5}$, JUSSI LIIPO ${ }^{5}$ AND VEERLE CNUDDE ${ }^{6}$ \\ ${ }^{1}$ PProGRess-UGCT, Geology Department, Ghent University \\ ${ }^{2}$ Helmholtz-Zentrum Dresden-Rossendorf, Helmholtz Institute \\ Freiberg for Resource Technology \\ ${ }^{3}$ Institute of Geology of Ore Deposits Mineralogy, Petrography, \\ and Geochemistry, Russian Academy of Sciences \\ ${ }^{4}$ TESCAN XRE \\ ${ }^{5}$ Metso Outotec \\ ${ }^{6}$ Ghent University \\ Presenting Author: margarita.merkulova@ugent.be
}

Norilsk ore deposits in Russia are one of the largest sources of Pt-group elements (PGEs) in the world. Palladium (Pd), the economically important critical element, one of the main metals mined in Norilsk, is found either in Pt-group minerals (PGMs) or as a trace element in pentlandite, $(\mathrm{Fe}, \mathrm{Ni})_{9} \mathrm{~S}_{8}[1]$. 2D distribution and high concentrations of Pd (up to 5 wt. $\%$ in pentlandite) in these minerals were recently demonstrated in Norilsk ores (Fig. 1) [2]. However, the trapping mechanism of Pd during the growth of sulphides and the nature of its incorporation into pentlandite are still under debate. It is generally accepted that PGEs can incorporate in sulphide minerals in form of separate atoms, metal clusters or as individual microscopic PGMs [3, 4]. So far, no direct evidence on Pd substitution in pentlandite is provided. Moreover, distribution of Pd on the atomic scale in PGMs is also unknown. In the present study we determine the chemical forms of $\mathrm{Pd}$ in natural pentlandite and PGMs from Norilsk ore deposit by combining synchrotron-based micro X-ray fluorescence $(\mu \mathrm{XRF})$ and high energy-resolution X-ray absorption spectroscopy (HR-XAS). The spectroscopic measurements are complemented by $3 \mathrm{D}$ micro computed tomography $(\mu \mathrm{CT})$ combined with spectral CT [5]. Synchrotronbased HR-XAS shows the atomic bonding environment of Pd in pentlandite, and common PGMs. In addition, we present a 3D distribution of chemically different PGMs and their relations with sulphide minerals. The new 3D data allows for an improved genetic model of the formation and enrichment of PGMs in the Norilsk ores. These results will help to develop more sustainable mining and the supply of PGEs, economically important critical metals.

Acknowledgements

This study has received funding from the European Institute of Innovation and Technology (EIT). This body of the European Union receives support from the European Union's Horizon 2020 research and innovation programme. The study was also supported by RFBR 18-05-70073.

[1] Sluzhenikin et al., Econ Geol, 115, 6 (2020)

[2] Brovchenko et al., Econ Geol, 115, 6 (2020)
[3] Junge et al., Miner Deposita, 50 (2015)

[4] Wirth et al., Can Mineral, 51 (2013)

[5] Sittner et al., X-ray Spectrom. (2020)

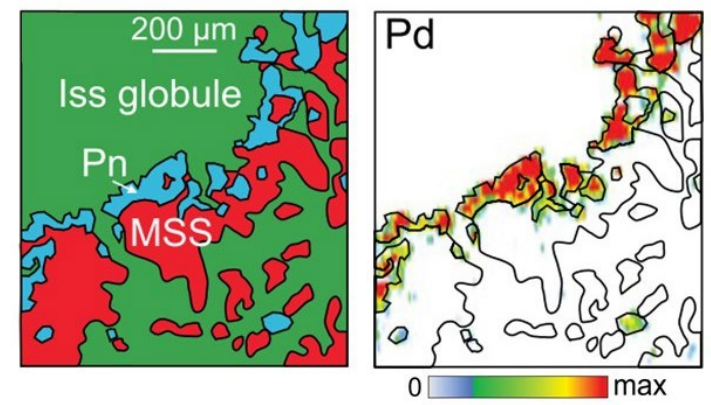

Left: schematic representation of fragment of sulphide globule (ISS and MSS) and pentlandite (Pn). Right: LA-ICP-MS map of Pd distribution in Pn. From Brovchenko et al. (2020). 